$\infty$

0

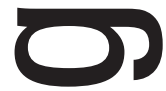

-

ת

1

$\longrightarrow$ 



\title{
PRODUÇÃO DE MATERIAL DIDÁTICO: JOGO DAS CURVAS DE NÍVEL
}

\author{
PRODUCTION OF EDUCATIONAL MATERIALS: GAME OF THE LEVEL CURVES
}

\author{
Cristiano Martins da Silva ${ }^{1}$ \\ crystiano_martins@yahoo.com.br \\ Gêijila Cristina Ferreira ${ }^{2}$ \\ geijila_cristina@yahoo.com.br
}

\section{RESUMO}

Muitos alunos apresentam aversão às aulas de geografia, classificando-as como cansativas e desinteressantes. Uma das razões para esta aversão é que os alunos não conseguem perceber como os conteúdos ensinados em sala de aula se relacionam ou até mesmo influenciam suas vidas. Com o objetivo de fazer com que as aulas de geografia se tornem mais interessante para os alunos, foi proposto pelo professor da disciplina Estágio Supervisionado I do curso de geografia da Universidade Federal de Goiás a elaboração de um material didático que servisse de auxilio ao ensino de geografia. A produção de material didático (quebra-cabeça, maquetes, blocos diagramas $\mathrm{e}$ jogos) oferece ao professor a possibilidade de trabalhar em sala de aula o cotidiano de seus alunos. Como material didático a ser produzido optou-se pela confecção de uma maquete. A maquete representou o relevo do bairro Jardim Balneário Meia Ponte, localizado na região Norte de Goiânia. Juntamente com a maquete foi elaborado um jogo que servisse para problematizar os temas abordados pela maquete e ao mesmo tempo permitir uma interação entre os alunos e professor. As etapas para produção da maquete e do jogo são apresentadas de forma detalhada no trabalho. Acreditasse que por meio da utilização do material didático em sala de aula o professor possa conseguir estimular em seus alunos a criatividade, a reflexão, o espírito critico e principalmente o desejo de aprender geografia.

Palavras-chave: material didático, maquete e cotidiano.

\section{ABSTRACT}

Many students dislike to geography class, they classify the class like tiring and uninteresting. One of the reason for this dislike is that students can not perceive how the content learned in the class to relate or influence his life. With the objective to do that class of geography make more interesting for the students, was proposed by the teacher of I supervise trainee discipline of the geography course of Universidade Federal de Goiás the elaboration the material that serve to auxiliary the teaching of geography. The production of didactic material (puzzle, maquette, block diagram and game) to offer the teacher the possibility to work in class the daily if their students. The didactic material will be produced we choose to make of the maquette. The maquette represented the relief of the district of Jardim Balneário Meia Ponte, located in the north region of Goiânia. United with maquette was elaborated a game that serve to render problematic the themes broach by the maquette and in the same time permit the interaction between the students and the teacher. The stages to production the maquette and the game will be present the detail form in the paper. To make oneself respected that by the utilization of didactic material in the class the teacher can be stimulated on their students the creativity, the reflection, the critic mind and principal the which to learn geography.

Key-words: didactic material, maquette, quotidian.

\begin{tabular}{|l|c|c|c|c|c|c|}
\hline Boletim Goiano de Geografia & Goiânia - Goiás - Brasil & v. 28 & n. 2 & p. 157-170 & jul. / dez. & 2008 \\
\hline
\end{tabular}





\section{Introdução}

A palavra escola, do latim schola, quer dizer "divertimento, recreação”, e em sua versão grega: scholé, "descanso, repouso, lazer, tempo livre, hora de estudo”. Se o sentindo original da escola quer dizer prazer, diversão, porque que a maioria das crianças apresentam aversão ao ambiente escolar? Muitas vezes, elas não compreendem porque deveriam estar estudando ao invés de fazer outras atividades mais agradáveis. Neste contexto, a escola está tão distante de sua dimensão lúdica que faz com que as crianças tenham resistência e desinteresse ao processo educativo. Conforme Macedo et al. (2005, p.16), "para elas, apenas o que é lúdico faz sentido. Em atividades necessárias (dormir, comer, beber, tomar, banho, fazer xixi), por exemplo, é comum as crianças introduzirem um elemento lúdico...”. Portanto, as atividades escolares devem valorizar a perspectiva lúdica da criança como forma de tornar mais atraente e motivador o processo de aprendizagem. Somente pela suas funções cognitivas, a criança ainda não consegue vislumbrar a escola como lugar que a capacitará para realizações da vida adulta. Outra razão para esta hostilidade é apontada por Castrogiovanni:

A escola não se manifesta atraente frente o mundo contemporâneo, pois não dá conta de explicar e textualizar as novas leituras da vida. A vida fora da escola é cheia de mistérios, emoções, desejos e fantasias, como tendem a ser as ciências. A escola parece homogênea, transparente e sem brilho no que se refere a tais características. (2000, p.13).

Muitos alunos não conseguem perceber como os conteúdos ensinados em sala de aula se relacionam ou até mesmo influenciam em suas vidas. Por isso torna-se fundamental que os professores, ao ensinar levem em consideração a realidade ou cotidiano de seus alunos, valorizando seus conhecimentos prévios. Como nos lembra Callai (2000, p.61): "Se a nossa preocupação é formar o cidadão, é ponto básico de partida que lhe oportunizemos as condições e os instrumentos para que conheça e compreenda a realidade em vive".

Ainda segundo Callai (2000), o aluno que sabe compreender a realidade em que vive é capaz de estudar questões e espaços mais distantes. Nesse contexto, a produção do material didático desempenha um importante papel em auxiliar os professores na organização de atividades de ensino. O material didático tanto estimula o interesse dos alunos para os conteúdos a serem 
estudados, como permite que o professor trabalhe em sala de aula o espaço vivido dos alunos. Conforme coloca Botelho et al. (2005, p.73),

As simulações mediante abordagens realizadas com material diverso, com preocupações voltadas para aspectos motivadores a exemplo de quebra-cabeça, maquetes, blocos diagramas e jogos são situações que envolvem o aluno despertando nele o interesse pelo conteúdo, e sua compreensão da realidade como um todo, alem do seu próprio papel dentro dessa realidade.

\section{A maquete como material didático para o ensino de geografia}

Com o objetivo de fazer com que as aulas de geografia deixem de ser extremamente cansativas e desinteressantes, estimular a reflexão, a criatividade, o espírito crítico e principalmente o desejo dos alunos de aprender, foi proposto pelo professor da disciplina Estágio Supervisionado I, do curso de geografia da UFG, a elaboração de um material didático que servi-se de auxílio ao ensino de geografia.

A produção do material didático proporcionou a possibilidade de trabalhar com o cotidiano do aluno. De trazer para sua realidade aquilo que está sendo estudado e demonstrar que a geografia é uma ciência “aplicável”, que não se restringe apenas ao livro didático. Como destaca Kaercher (2000, p.15):

A geografia é feita no dia-a-dia, seja através da construção de uma casa, da plantação de uma lavoura ou através das decisões governamentais ou dos grupos econômicos (empresas transnacionais). Ou ainda, em nossas andanças, ações individuais pela cidade (pegar um ônibus, fazer compras, etc.).

Como material didático a ser produzido optou-se pela confecção de uma maquete. Conforme a definição de Castrogiovanni (2000, p. 74):

A maquete é um modelo tridimensional do espaço. Ela funciona como um laboratório geográfico, onde as interações sociais do aluno no seu dia-a-dia são passiveis de serem percebidas quase que na sua totalidade. A construção da maquete é um dos primeiros passos para um trabalho mais sistemático das representações geográficas.

Sua utilização como auxilio ao ensino, não é uma idéia nova, vários autores já trabalharam nessa perspectiva (Simielli, Pinheiro, Castrogiovanni, 
Lombardo \& Castro). A maquete pode ser estática ou dinâmica. A maquete estática permite somente a observação dos elementos espaciais ali representados. Ao contrário da estática, a maquete dinâmica permite, não somente a observação, como também a intervenção levando os alunos a desenvolverem o senso crítico daquilo que está sendo representado.

A maquete serve para auxiliar os professores e, principalmente, permite que os alunos compreendam os conteúdos geográficos estudados em sala de aula. A maquete proposta na atividade de Estágio I representou o relevo do bairro Jardim Balneário Meia Ponte, localizado na região Norte de Goiânia.

\section{Escolha da área}

Localizado na margem direita do Rio Meia Ponte (Figura 1), o Jardim Balneário Meia Ponte é um dos 17 bairros que fazem parte desse sistema de drenagem dentro da Região Metropolitana de Goiânia. Atravessando o município no sentido noroeste-sudeste, esse rio é um significativo agente modelador do relevo da cidade. Goiânia possui duas Estações de Tratamento de Água (ETA): a primeira é a ETA Meia Ponte, na região Noroeste, e a outra é a ETA do João Leite, afluente do Rio Meia Ponte, situada na Região Norte de Goiânia. Deve-se ressaltar a importância desse manancial de água na drenagem da malha urbana e abastecimento para uso público.

O Jardim Balneário Meia Ponte é um bairro antigo da cidade de Goiânia. Foi criado por volta de 1965, trinta e dois anos depois que a cidade de Goiânia foi construída. É um bairro residencial, que possui construções em sua grande maioria horizontalizadas e de alvenaria. Possui serviços de água encanada, luz elétrica, esgoto e ruas pavimentadas. No bairro encontram-se dez escolas, sendo duas estaduais, três municipais e cinco da rede privada, além de um comércio local bem estruturado.

Contudo, várias casas foram construídas no fundo de vale do Rio Meia Ponte e, com isso, na época das chuvas torrenciais esses moradores têm seus quintais alagados e, não raras vezes, suas casas também. A impermeabilização promovida pelo asfalto, associada à construção do bairro em uma grande vertente, faz com que grande parte das águas das chuvas vá direto para o leito do rio, aumentando a vazão e transbordando para as margens, que estão ocupadas por habitações. 


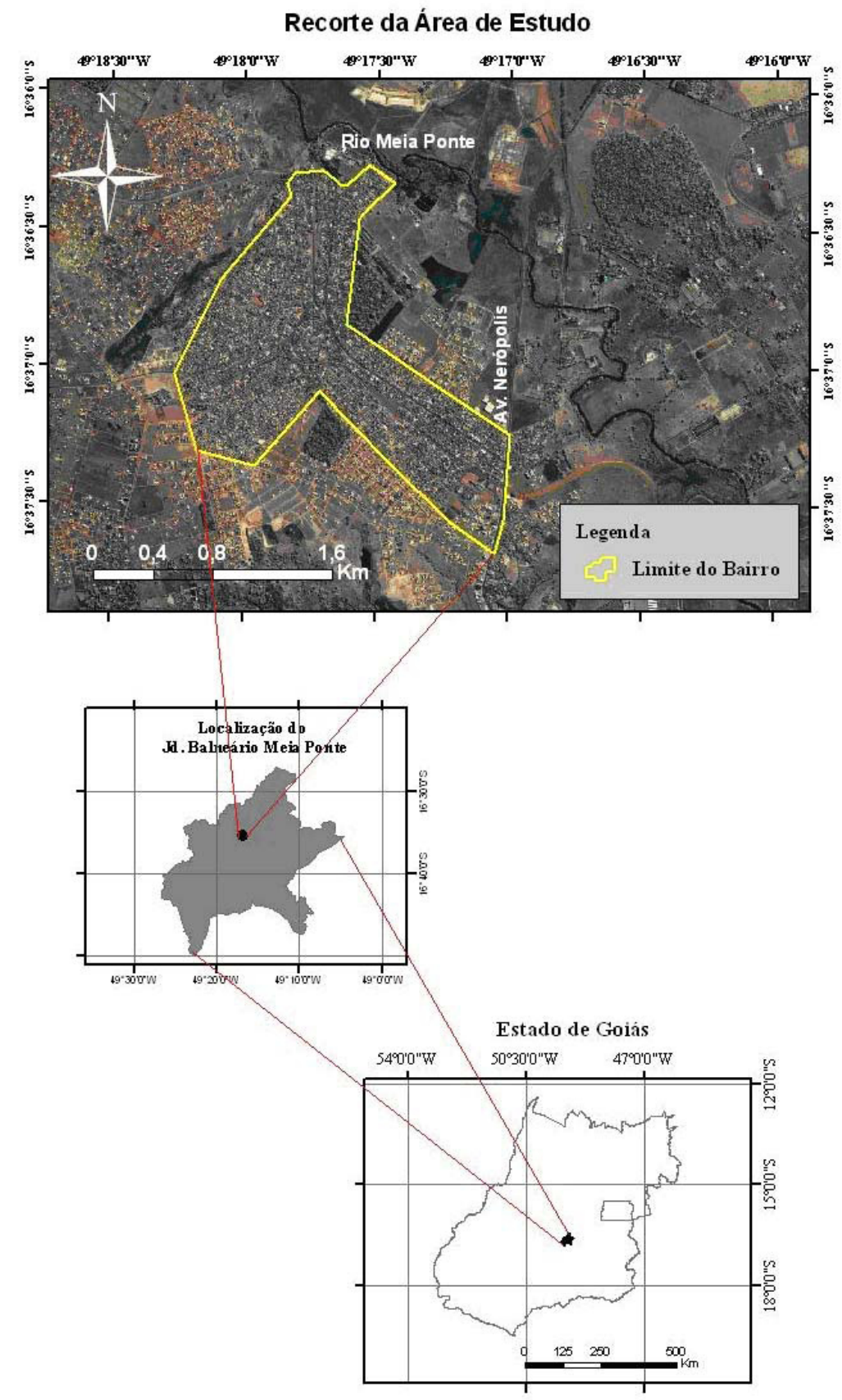


Áreas como estas exemplificam bem conteúdos que são trabalhados na disciplina de geografia como, hidrografia, áreas de risco (áreas sujeitas à inundação e erosão), uso e ocupação do solo e impactos ambientais. Quando o professor juntamente com os seus alunos reproduz áreas como estas por meio de maquetes, torna mais fácil para eles perceberem como a geografia está presente em seu dia-a-dia. Isso faz com que os alunos passem a olhar as coisas a sua volta, como o bairro em que vivem com um novo olhar, um olhar geográfico.

Segundo Collischonn (1997, p.87), “A maquete não deve ser considerada como um fim didático, mas, sim, um meio através dos quais os diversos elementos da realidade local possam ser trabalhados". Nessa perspectiva o conteúdo se torna fundamental para elaborar e compreender a maquete. Por isso é pertinente explicar alguns termos que permitem uma melhor exploração da atividade.

\section{A definição de relevo}

A superfície da Terra apresenta desigualdades de formas e grande variedade de aspectos. Essas desigualdades que existem na superfície da Terra recebem o nome de relevo. O relevo terrestre pode ser definido como as formas da superfície do planeta. O relevo se origina e se transforma sob a interferência de dois tipos de agentes: internos e externos. Os agentes internos são chamados de endógenos como o vulcanismo e o tectonismo e os agentes externos são chamados de exógenos como o intemperismo e a antropicidade. É comum nos livros didáticos a divisão do relevo terrestre em: planalto, montanhas, planícies e depressões, que são as formas e termos mais comuns.

\begin{tabular}{|l|l|}
\hline Tipo & Exemplos \\
\hline Montanhas & Andes (América do Sul), Himalia (Ásia) e Alpes (Europa) \\
\hline Planaltos & Planalto Central Brasileiro \\
\hline Planícies & Planície do Pantanal, Planície Amazônica e Planície Costeira. \\
\hline Depressão & Depressão do Araguaia e Depressão do Tocantins \\
\hline
\end{tabular}

\section{Mapa topográfico}

Mas o relevo é bem mais complexo que a compartimentação apresentada nesse quadro que tem finalidade didática. Nesse sentido, dependendo 
da maturidade dos alunos, é possível inserir a abordagem de formas e compartimentações mais complexas como por meios dos mapas topográficos. Estes mapas se caracterizam pela representação detalhada do relevo. Por meio deles podemos identificar morros, vales, escarpar, colinas, depressões, etc. O que caracteriza um mapa topográfico é a presença de curvas de nível e pontos cotados. As curvas de nível, também chamadas de isoípsas ou linhas hipsométricas, são, portanto, uma convenção cartográfica utilizada para representar as variações da superfície topográfica. Pode-se imaginar o traçado das curvas de nível como sendo as secções (fatias) retiradas de um relevo mantendo-se um espaçamento constante entre as mesmas.

\section{Etapas da elaboração do material idático}

Os procedimentos de elaboração da maquete são constituídos das seguintes etapas:

\section{$1^{\mathrm{a}}$ - Aquisição da carta topográfica}

- $\quad$ Estes mapas podem ser elaborados através de alguns programas computacionais (ArcGIS, ArcView, TerraView, SPRING, Geomedia, MapInfo e outros) que tem por objetivo produzir informações geograficamente referenciadas, a partir do processamento de dados geográficos. Também podem ser extraídos de cartas topográficas impressas;

- Definição da escala horizontal e vertical. A escala horizontal costuma ser a mesma da carta topográfica. No exemplo aqui demonstrado, a escala utilizada é 1/50.000 (1 centímetro no mapa equivale a 500 metros no terreno). A escala vertical deve ser definida conforme a topografia da área, com a eqüidistância das curvas de nível e de acordo com a espessura do material utilizado na confecção da maquete. Sendo assim, a carta do Bairro Jd. Balneário Meia Ponte possuía uma eqüidistância de 10 metros, utilizando-se de lâminas de borracha E.V.A. (Etil vinil acetato) de 0,4 cm de espessura, teremos uma escala vertical de 1/2.500. Este cálculo é obtido dividindo-se ao valor da eqüidistância (10 m) pela espessura da lâmina de borracha E.V.A. $(0,4 \mathrm{~cm})$. Depois, converte-se o resultado, dado em metros, para centímetros, e tem-se a escala numérica vertical. 
- Este cálculo é obtido pela seguinte operação:

$$
10 \mathrm{~m} / 0,4 \mathrm{~cm}=25(\mathrm{~m})=2.500 \mathrm{~cm}
$$

- Um parâmetro inicial é testar a escala vertical idêntica à horizontal (1/50.000) e verificar diferentes espessuras de E.V.A. Se o desnível for pequeno (curva maior menos curva menor), isto é, se o relevo for mais suave, é interessante ampliar a escala vertical (ex: 1/1.250) ou aumentar a espessura do E.V.A. (ex: 8 milímetros) para destacar as diferenças de nível. Caso o relevo seja muito dissecado, é interessante diminuir a escala para suavizar as variações do relevo ou diminuir a espessura do E.V.A. (ex. 2 milímetros). A espessura da lâmina não deverá ser muito grossa (ex: 10 milímetros), pois quanto mais grossa, maior será a dificuldade para recortar a placa com a forma irregular das curvas de nível.

\section{$2^{\text {a }}$ - Seleção do material utilizado}

\begin{tabular}{|c|l|l|}
\hline iItem & Materiais & Onde Adquirir \\
\hline \multirow{2}{*}{01} & $\begin{array}{l}\text { Cópia da Carta Topográfi- } \\
\text { ca; }\end{array}$ & $\begin{array}{l}\text { Desenvolvido por um SIG (Sistema de Infor- } \\
\text { mações Geográficas). O SPRING é um exem- } \\
\text { plo de SIG que pode ser baixado gratuitamente } \\
\text { no site: http://www.dpi.inpe.br. }\end{array}$ \\
\hline \multirow{2}{*}{02} & $\begin{array}{l}\text { Lâmina de borracha E.V.A. } \\
\text { (Etil vinil acetato). Cada lâ- } \\
\text { mina corresponderá a uma } \\
\text { curva de nível; }\end{array}$ \\
\hline \multirow{2}{*}{ F5 } & Lápis & \\
\cline { 2 - 2 } & Tesoura ou estilete & \multirow{2}{*}{ Papelarias } \\
\cline { 2 - 2 } & Papel vegetal e carbono & \\
\cline { 2 - 2 } & $\begin{array}{l}\text { Cola especial para E.V.A. } \\
\text { (Etil vinil acetato) }\end{array}$ & \\
\hline \multirow{2}{*}{07} & $\begin{array}{l}\text { Alfinete com cabeça gran- } \\
\text { de }\end{array}$ & \\
\hline \multirow{2}{*}{08} & $\begin{array}{l}\text { Placa espessa de madeira } \\
\text { (com espaço para a maque- } \\
\text { te e o tabuleiro do jogo); }\end{array}$ & \multirow{2}{*}{ Madeireiras } \\
\hline
\end{tabular}




\section{$3^{\mathrm{a}}$ - Construção da maquete}

- $\quad$ Sobre o mapa base (Fig.2), sobrepor o papel vegetal e realizar a cópia de cada curva de nível em uma folha separada.

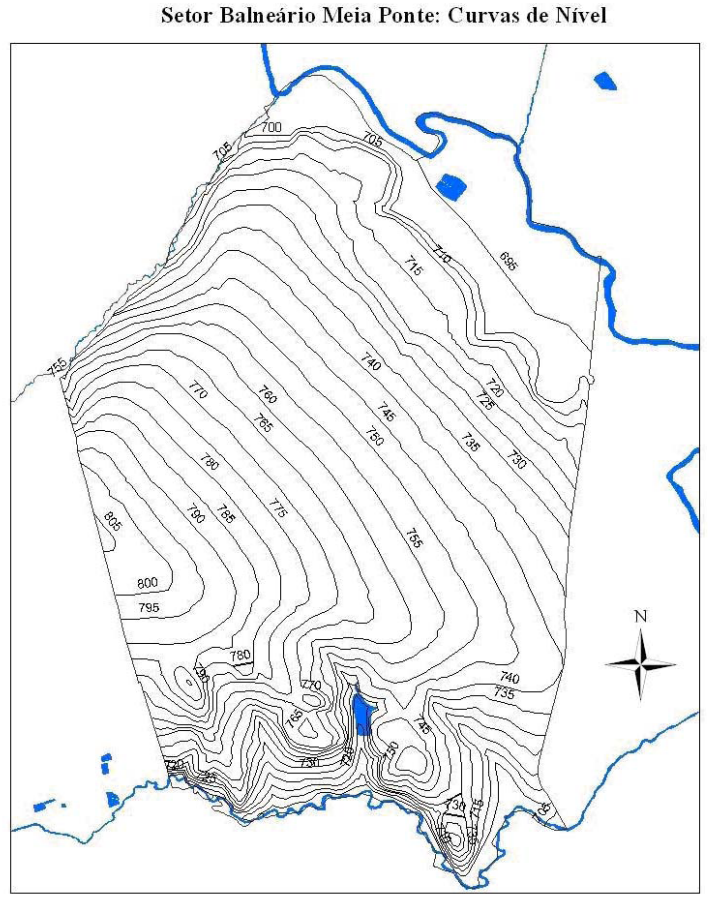

- Transferir os contornos para o E.V.A. Para isso intercala-se entre o E.V.A. e cada papel vegetal correspondente a uma curva de nível, uma folha de papel carbono. Para ressaltar a variação das curvas de nível, deve-se transferir os contornos para E.V.A. de cores diferentes. Para as curvas de nível de altitudes maiores devem se usar cores quentes (amarelo, laranja e vermelho) e, para as menores, cores frias (violeta, azul e verde).

- $\quad$ Em seguida, perfura-se com alfinete todo o contorno, ficando a curva de nível demarcada no E.V.A.

- $\quad$ Recortar os E.V.A. e colar um sobre o outro, partindo das menores altitudes para as maiores. (Figura 2). 


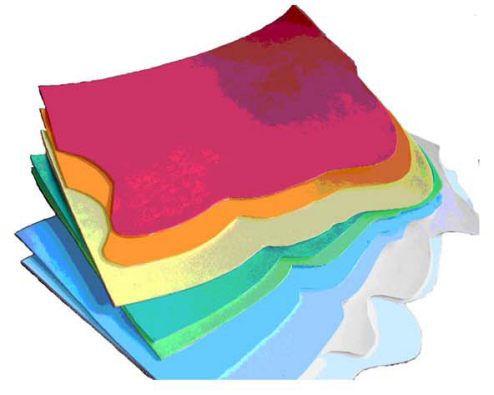

Fig. 2 - Maquete com as curvas de nível cortadas. Prontas para serem coladas.

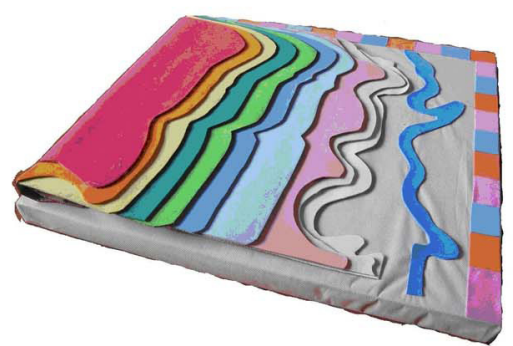

Fig. 3 - Maquete pronta. Cada cor representa uma cota altimétrica.

- $\quad$ Colar a maquete sobre uma base ou suporte (Figura 3).

\section{Jogo das curvas de nível}

Com a maquete construída, priorizou-se a elaboração de um jogo que servisse para problematizar os temas abordados pela maquete e, ao mesmo tempo, permitisse uma interação entre os alunos e o professor. O jogo elaborado recebeu o nome de "jogo das curvas de nível”. Ele permite a participação de quatro equipes de jogadores. O número de integrantes de cada equipe dependerá do número de alunos em sala.

\section{Materiais necessários}

- 1 (um) dado.

- $\quad$ Cartões de perguntas.

- $\quad$ Miniaturas de casas, escolas, lojas, fabricas e outros elementos do espaço urbano.

\section{Regras do jogo}

- $\quad$ Cada equipe deverá estar representada por uma cor: verde, amarelo, laranja e vermelho;

- A cor designada a cada equipe também corresponderá à cor de seus cartões-pergunta, enumerados de um a seis. Cada cartão- 
pergunta deverá abordar conteúdos já estudados em sala de aula e propor atividades relacionadas à maquete, para que os alunos as executem.

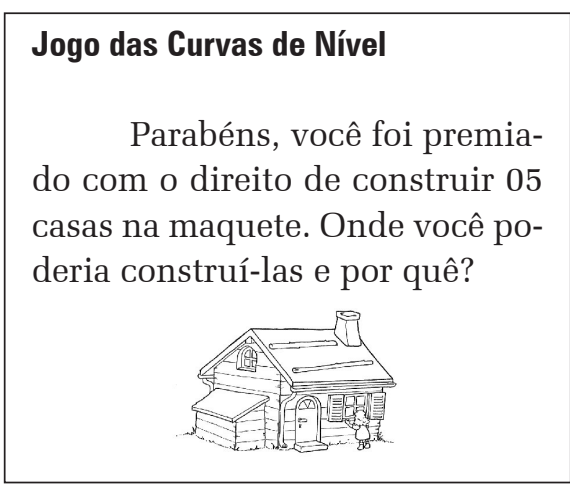

\section{Jogo das Curvas de Nível}

Indique quais são as cotas altimétricas mais próximas uma das outras o que e isso revela sobre o relevo

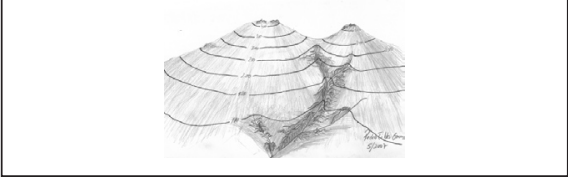

\section{Jogo das Curvas de Nível}

Se você fosse pavimentar o bairro, em qual sentido das ruas às águas da chuva escoariam com maior velocidade? Justifique sua resposta.

\section{Jogos das Curvas de Nível}

Você foi indicado pelo prefeito para reflorestar uma área. Indique esta área na maquete.

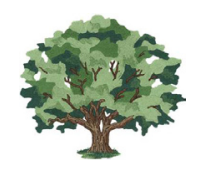

\section{Jogo das Curvas de Nível}

Peça para seu professor traçar duas linhas na maquete. Depois responda: Se você fosse fazer uma caminhada seguindo um dos trajetos qual deles escolhe-ria? Por quê?

\section{Jogo das Curvas de Nível}

Trace uma linha na maquete e elabore um perfil topográfico do terreno. 
- Cada equipe deverá eleger um representante e estes irão decidir na sorte quem começa o jogo. Estabelecida a ordem, um dos jogadores deverá jogar o dado. O número sorteado corresponderá ao numero do cartão-pergunta que a equipe deverá ler e resolver o problema proposto. Após todos os cartões lidos, o professor deverá verificar qual equipe conseguiu resolver corretamente um número maior de problemas propostos pelo jogo.

\section{Aplicabilidade}

A finalidade da produção, tanto da maquete quanto do jogo é trazer a realidade ou cotidiano do aluno para dentro da sala de aula. A partir da maquete, pode-se estimular os alunos a realizar uma análise integrada da paisagem, através da discussão de temas como: uso do solo, hidrografia, ação antrópica, constituição do solo, tipo de vegetação, entre outros. Mas para que os alunos consigam perceber a relação que existe entre os conteúdos geográficos e sua vida, é indiscutível o papel do professor. Segundo Castrogiovanni (2000), o professor deve ser um agente desequilibrador, responsável por problematizar e dramatizar.

Como nos lembra Lacoste (1986), não há geografia sem drama e tudo nesta disciplina pode e deve ser dramatizado. O professor deverá levar seus alunos a refletir em suas ações, na resolução de cada atividade. Sem esta intervenção, a maquete terá função apenas ilustrativa.

* Resultado de pesquisa desenvolvida na disciplina estágio supervisionado II, sobre a orientação do professor Tadeu Alencar Arrais

\section{Referências}

BOTELHO, L.A.L. A; SILVEIRA, J.S; ANDRADE, S.N. Caderno de geografia, Belo Horizonte, v.15, n.25, p.60-76, $2^{\circ}$ sem. 2005

CALLAI, H.C. O ensino de geografia: recortes espaciais para análise. In: CASTROGIOVANNI, A.C. (Org) Geografia em sala de aula: práticas e reflexões. $4^{\circ}$ ed. Porto Alegre: UFRGS/Associação dos Geógrafos Brasileiros, 2003. p. 57-63. 
CASTROGIOVANNI, A.C. (Org) Ensino de geografia: práticas e textualizações no cotidiano. Porto Alegre: Medição, 2000.

COLLICHONN, E. Maquetes de municípios-um recurso didático. Agora, Santa Cruz do Sul, v.3, n.1, p.75-89, jan/jun. 1997.

KAERCHER, N.A. A geografia é o nosso dia-a-dia. In: CASTROGIOVANNI, A.C. (Org) Geografia em sala de aula: práticas e reflexões. $4^{\circ}$ ed. Porto Alegre: UFRGS/Associação dos Geógrafos Brasileiros, 2003. p. 11-21.

Lacoste, Y. La Ensenanza de la Geografia. Curso proferido dias 22 e 23 de março de 1985 na Universidade de Salamanca, Espanha, editado em 1986 pelo grupo Cronos.

Cristiano, Martins Silva - Graduando em geografia pela - UFG

Gêijila Cristina - Graduando em geografia pela - UFG

Recebido para publicação abril de 2008

Aceito para publicação outubro de 2008 